\title{
Light-Weight Multi-Walled Carbon Nanotube Buckypaper/Glass Fiber-Epoxy Composites for Strong Electromagnetic Interference Shielding and Efficient Microwave Absorption
}

\section{Bruno Ribeiro ( $\nabla$ dorado.bruno@gmail.com )}

Universidade Federal de Sao Paulo https://orcid.org/0000-0002-0078-9641

Newton Adriano Gomes

UNIFESP: Universidade Federal de Sao Paulo

Mirabel Cerqueira Rezende

UNIFESP: Universidade Federal de Sao Paulo

Original Research

Keywords: Carbon nanotube, Buckypaper, Electromagnetic interference shielding effectiveness, absorbing material

Posted Date: February 12th, 2021

DOl: https://doi.org/10.21203/rs.3.rs-190446/v1

License: (c) (1) This work is licensed under a Creative Commons Attribution 4.0 International License.

Read Full License 
Light-weight multi-walled carbon nanotube buckypaper/glass fiber-epoxy composites for strong electromagnetic interference shielding and efficient microwave absorption

\author{
Bruno Ribeiro*, Newton Adriano Santos Gomes, Mirabel Cerqueira Rezende \\ Instituto de Ciência e Tecnologia, Universidade Federal de São Paulo (UNIFESP), São José dos Campos, \\ São Paulo, Brasil. \\ Corresponding author: dorado.bruno@gmail.com
}

\begin{abstract}
Multi-walled carbon nanotube buckypaper (BP) reinforced glass fiber-epoxy (GF/EP) composites were selected to fabricate electromagnetic interference (EMI) shielding and microwave absorbing composites. Six different composite configurations with $3.0 \mathrm{~mm}$ thick have been conceived and tested over the X-band (8.2-12.4 GHz). Flexible and low density $\left(0.29 \mathrm{~g} / \mathrm{cm}^{3}\right)$ BP provided a high specific EMI SE of $55 \mathrm{~dB}$ with controlled electrical conductivity. $\mathrm{GF} / \mathrm{EP} / \mathrm{BP}_{111}$ and $\mathrm{GF} / \mathrm{EP} / \mathrm{BP}_{101}$ composites possess EMI SE as high as of 50-60 dB, which can be attributed to the number of BP inserted and variation in the wave-transmitting layer of the laminates. Furthermore, the shielding mechanism was discussed, and it suggested that the dominant contribution to EMI SE was absorption. $\mathrm{GF} / \mathrm{EP} / \mathrm{BP}_{110}$ laminate demonstrated suitable EMI performance $(\sim 20 \mathrm{~dB})$ and excellent microwave performance, achieving an effective $-10 \mathrm{~dB}$ bandwidth of $3.04 \mathrm{GHz}$ and minimum reflection loss (RL) value of $-21.16 \mathrm{~dB}$ at $10.37 \mathrm{GHz}$. On the basis of these results, GF/EP/BP composites prepared in this work have potential applications as both EMI shielding and microwave absorber materials given their facile preparation and lightweight use.
\end{abstract}

Keywords: Carbon nanotube, Buckypaper, Electromagnetic interference shielding effectiveness, absorbing material. 


\section{Introduction}

Over the last years, the need for shields or absorber materials has been attracting more and more attention from both academic and industrial fields due to the substantial increase in the usage of electronic devices, that generate several forms of electronic pollutions, such as electromagnetic radiation, electromagnetic interference (EMI), electronic noise, among others [1-3]. Electromagnetic radiation can also affect human health, with some works reporting severe diseases such as brain tumors [4] and leukemia [5].

EMI shielding can be understood as the ability to reflect and/or absorb EM radiation by a barrier made of conductive materials [6,7]. Conventional metal-based EMI shielding materials (e.g., copper, nickel, aluminum, magnesium, and zinc) have been the target point of the researchers for years, due to their notable EMI shielding effectiveness (SE) being attributed to high electrical conductivity $[8,9]$. However, several reasons can be pointed out using metals such as high density, poor processability, and corrosion, which can limit their EMI applications in real structures. Moreover, metallic materials mostly reflect or scatter the EM radiation into their surroundings, which may cause additional issues. Based on these features, novel EMI shielding materials are highly recommended, not only for better EMI shielding performance but also for developing microwave absorbing materials that efficiently convert the EM radiation into thermal energy.

Multiscale composites (MC) are a novel type of polymer composites that consist of a polymer matrix reinforced with microscale (fibers) and nanoscale materials [10]. Carbon nanotubes (CNTs) have been extensively studied as a promising high-performance absorbing material mainly due to their high aspect ratio, prominent electrical and thermal conductivities, low density, chemical inertness, and outstanding mechanical properties [11-13]. The aforementioned features qualify the CNTs as one of the ideal nanomaterials to be incorporated in the traditional fiber-reinforced polymer composites. Furthermore, 
CNT-polymer composites have been one of the major research topics over the last years, particularly due to the possibility to reach high EMI SE properties and their significant advantages like lightweight and good processability over the metal-based shielding materials [14-17].

Uniform dispersion of the fillers is the major concern for CNT-polymer composites. However, the strong van der Waal's forces between the tubes make them easy to agglomerate when dispersed in polymer matrices, which may decrease the final shielding properties of the material. Huang and co-workers [18] prepared single-walled carbon nanotube/epoxy composites with high CNT concentration (15\%). The EMI results exhibited by the $2 \mathrm{~mm}$ thick composite were only 20-30 dB, which can be attributed to the poor dispersion level of the filler in a polymer matrix. As an alternative to dispersion issues, carbon nanotube films, also known as buckypapers (BP), have been employed in CNT-polymer composites revealing promising EMI applications. BP can be prepared by vacuum filtration of a suspended dispersion of randomly distributed carbon nanotube, showing a wide range of applications, including EMI shielding material [19].

Furthermore, as discussed by several authors [20-22], the high electrical conductivity of the BP $(50-6000 \mathrm{~S} / \mathrm{m})$ can result in high SE properties. Shaowei Lu et al. [23] prepared a hybrid single/multi-walled carbon nanotube buckypaper by vacuum filtration with an average thickness of around $50 \mu \mathrm{m}$. The CNT film showed low density (0.76 $\left.\mathrm{g} / \mathrm{cm}^{3}\right)$ and reached high levels of electrical conductivity $(5000 \mathrm{~S} / \mathrm{m})$ with outstanding EMI SE performance of $\sim 55 \mathrm{~dB}$ in X-band (8.2-12.4 GHz). Qianshan Xia and collaborators [24] prepared buckypaper/polyacrylonitrile (BP/PAN) films based on electrospun and vacuum pressurized filtration methods. The BP/PAN films exhibited higher EMI SE values $(65 \mathrm{~dB})$ in Ku-band (12-18 GHz) than pristine BP (34.3-42.9 dB), and the dominant shielding mechanism was the reflection. $\mathrm{Zi}$ Ping $\mathrm{Wu}$ and co-workers 
[25] prepared a free-standing CNT mat through a floating catalyst chemical vapor deposition method, with a thickness of $1 \mu \mathrm{m}$ and high electrical conductivity. The high EMI SE of 40.4-60.3 dB was achieved at the frequency range of 1-18 GHz, demonstrating the CNT mat has potential applications as a shielding material.

Carbon nanotube buckypaper and buckypaper composites have recently received great attention from both academic and industrial fields, appearing possibly as the next generation of EMI shielding materials due to their efficient microwave attenuation capacity and low density. Furthermore, a material that combines flexibility and tailored conductivity could be manufactured as shielding clothes, to guarantee the security of data information and the people's health. In this contribution, a flexible carbon nanotube buckypaper was prepared by vacuum filtration with the assistance of PAN mats through the electrospinning process. The prepared CNT films were incorporated between the glass fiber/epoxy (GF/EP) layers, and the composite system was cured in hot press. Meanwhile, EMI shielding properties of $\mathrm{BP}$ and GF/EP/BP composites obtained from the scatter parameters were characterized over the X-band frequency range.

\section{Experimental}

\subsection{Materials}

Multi-walled carbon nanotubes (MWCNTs) were supplied by Bayer (Baytubes C150P) and synthesized by chemical vapor deposition (CVD) method. The average diameter of tubes is in the range of $10 \mathrm{~nm}$ and length 10-20 $\mu \mathrm{m}$. Glass fiber/epoxy layers were prepared by manual lamination using two main components: Epoxy resin (Araldite ${ }^{\circledR}$ GY 279 BR - Huntsman) attending the ratio of 100:6 resin/harder and glass fiber (Owens Corning - TLX0750), plain weave with areal fiber density of $600 \mathrm{~g} / \mathrm{m}^{2}$. 
Preparation of Buckypapers

Vacuum filtration was used to prepare the buckypapers, and the procedure was described in detail in our previous work [26]. MWCNTs $(50-200 \mathrm{mg})$ were ultrasonically dispersed in deionized water with $1 \mathrm{wt} \%$ of Triton $\mathrm{X}-100^{\circledR}$ surfactant for 40 min to obtain a uniform suspension. Before filtering, four layers of polyacrylonitrile nanofibers (PANF) were stacked over a nylon ${ }^{\circledR}$ microporous filter $(0.45 \mu \mathrm{m})$, aiming for improved flexibility of the CNT film. PANF was prepared using the electrospinning process according to our previous work[27]. The CNT/water/surfactant suspension was filtered over the PANF/nylon ${ }^{\circledR}$ membrane under vacuum conditions. The obtained buckypaper was rinsed with acetone and isopropyl alcohol to remove the residual surfactant and then immersed into $\mathrm{N}, \mathrm{N}$-dimethylformamide $(\mathrm{DMF})$ bath $\left(50{ }^{\circ} \mathrm{C}\right)$ several times to dissolve the PANF. The obtained buckypaper was dried at $80{ }^{\circ} \mathrm{C}$ in a vacuum oven before any further test and use.

\subsection{Preparation of glass fiber/epoxy/buckypaper laminates}

Glass fiber/epoxy layers were manually stacked over $(70 \times 70) \mathrm{mm}^{2}$ steel mold so that BPs were introduced between the prepregs layers forming a sandwich structure with a final thickness of $3 \mathrm{~mm}$. A Kapton ${ }^{\circledR}$ film was employed as a release agent, and the system was cured in a hot-press at $150{ }^{\circ} \mathrm{C}$ for two hours under $0.5 \mathrm{MPa}$. The position and the number of BP inserted in the laminate were deeply studied, generating several configurations described in Fig. 1. 


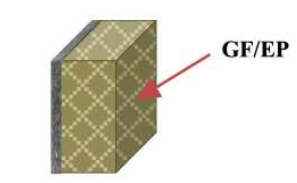

GF/EP/BP 100

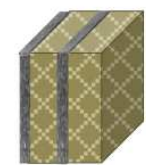

GF/EP/BP 110

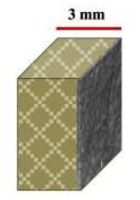

GF/EP/BP001

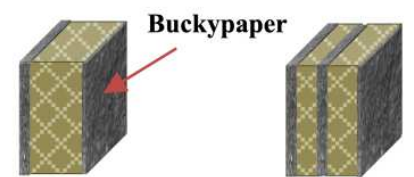

GF/EP/BP 101

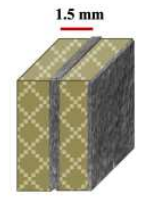

GF/EP/BP 011

GF/EP/BP 111

Fig. 1 Schematic configuration studied for GF/EP/BP laminates.

\subsection{Characterization}

The crystalline structure of the MWCNTs was evaluated at room temperature by wide-angle X-ray diffraction (XRD) (Rigaku X-ray diffractometer model Ultima IV) using $\mathrm{Cu} \mathrm{K} \square$ radiation $\left(\square=1.54178 \AA\right.$ ), at a scanning rate of $0.01^{\circ}$ (fast detection mode) and a scan speed of $10^{\circ} / \mathrm{min}$. Diffractograms were obtained in the angular region of $2 \square=$ $10-60^{\circ}$

X-ray photoelectron spectroscopy (XPS) analyses were performed with Axis Ultra DLD spectrometer using a monochromatized Al X-ray source $(1486.6 \mathrm{eV})$ for both MWCNTs and BP. Casa XPS software was used to analyze the obtained data.

Morphological characteristics of BP were analyzed by scanning electron microscopy (SEM) (FEI Inspect S50) at an acceleration voltage of $20 \mathrm{kV}$. This equipment is assisted with the energy-dispersive X-ray spectroscopy (EDS). Before observation, the samples were sputtered with a thin golden layer under vacuum to avoid charging during electron irradiation, except those used for the EDS analyses. High-resolution transmission electron microscopy (HRTEM) (FEI Tecnai G2F20) was employed to evidence the morphology of the individual CNT at an acceleration voltage of $200 \mathrm{kV}$.

Two-point probe device (Agilent B2912A) was used to measure DC conductivity 
of the samples at room temperature. The conductivity $\rho_{\mathrm{v}}$ can be calculated based on Equation 1:

$$
\rho_{v}=\frac{t}{A} \cdot \frac{1}{R_{v}}
$$

where: $A$ is the area of the laminate, $t$ is thickness, and $R_{v}$ is the volume resistance of the specimen, respectively.

Electromagnetic interference shielding performance of the composites was measured with a vector network analyzer from Agilent Technologies (PNA-L N5230C). The scattering parameters $\left(S_{11}\right.$ and $\left.S_{21}\right)$ in the $X$-band were recorded to calculate the reflected power (R), transmitted power (T), absorbed power (A), and EMI SE parameters $\left(\mathrm{SE}_{\mathrm{T}}, \mathrm{SE}_{\mathrm{A}}\right.$, and $\left.\mathrm{SE}_{\mathrm{R}}\right)$ for all studied samples.

\section{Results and discussions}

\subsection{Morphology of the buckypaper}

The morphology of the prepared buckypaper in this work was investigated by SEM, as showed in Fig. 2(a-b). The CNT film has a thickness of about $50-100 \mu \mathrm{m}$, a bulk density of $\sim 0.29 \mathrm{~g} / \mathrm{cm}^{3}$, and its surface consists of a randomly distributed MWCNTs revealing a porous network with no local aggregation of the tubes. Moreover, the combination of the van der Waals forces and $\pi-\pi$ interactions between the tubes make the MWCNT bundles very close to each other, resulting in a denser film. Fig. 2c presents a different region of the buckypaper sample and Fig. 2d displays the cross-section view of the CNT film showing tunnels/channels that were formed from the dissolution of the PANF by DMF. As already mentioned in this work, the introduction of PANF (with an average diameter of around $300-400 \mathrm{~nm}$ ) provided great flexibility to the $\mathrm{BP}$, making the lamination of the composites, by stacking GF/EP layers and BPs, an easier task. Fig. 2(ef) shows the HRTEM image of the buckypaper. As can be observed, there are long entangled bundles with a diameter of $10-20 \mathrm{~nm}$ with no catalyst particles that are common 
from the synthesis process of the MWCNTs. Also, small fragments of the tubes can be visualized as well (Fig. 2e), indicating the CNT nanofilaments were possibly damaged during the preparation of the buckypaper and/or during the functionalization process of the MWCNTs.
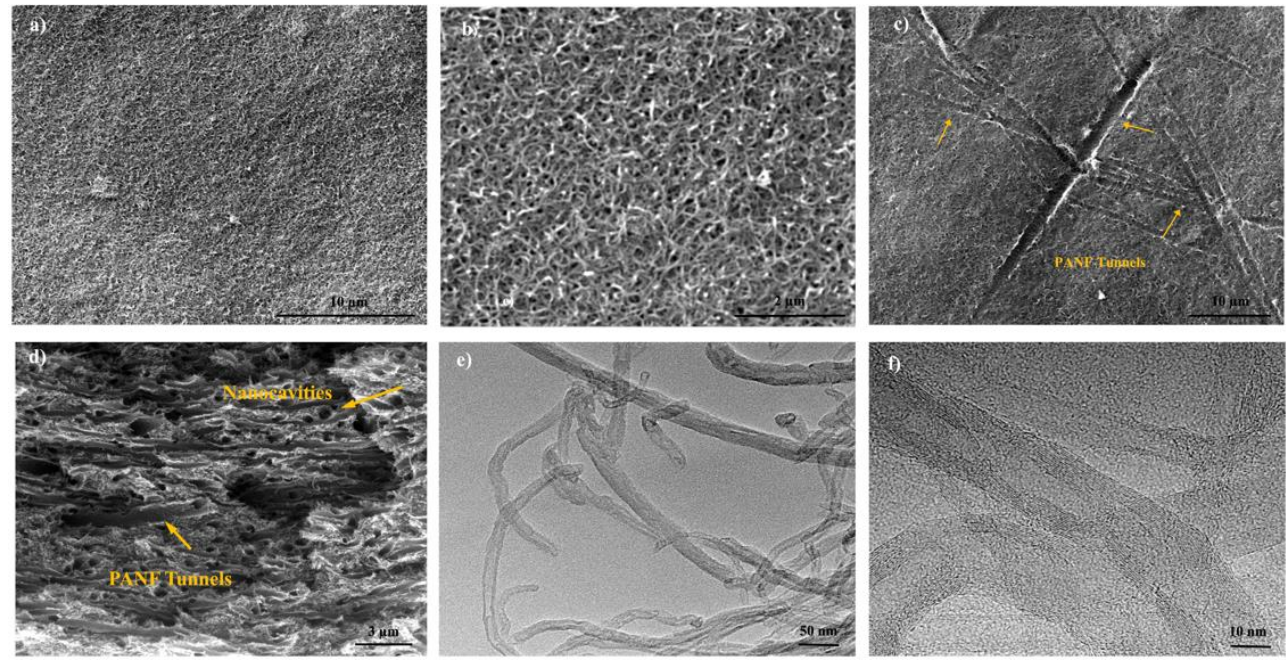

Fig. 2 SEM images of buckypaper with different magnifications (a-b), PANF tunnels on the BP structure (c-d) and, HRTEM of the prepared buckypaper (e-f).

A typical XRD pattern of MWCNT is depicted in Fig. 3a. It can be clearly observed that the MWCNT sample has two broad diffractions peaks centered at about $25.9^{\circ}$ and $43.5^{\circ}$, which can be ascribed to the characteristic planes (002) and (100) of graphitic carbons [28]. XPS analyses were used to investigate the incorporation of functional groups on the MWCNT surface (Fig. 3b) and in the prepared buckypaper (Fig. 3c). According to the full scan XPS spectra of the MWCNT and the BP, both samples show the obvious commons peaks of $\mathrm{C} 1 \mathrm{~s}$ and $\mathrm{O} 1 \mathrm{~s}$ at $287 \mathrm{eV}$ and $532 \mathrm{eV}$, respectively. C1s can be attributed to the $\mathrm{C}=\mathrm{O}, \mathrm{C}-\mathrm{O}$, and $\mathrm{C}-\mathrm{C}[29]$, whereas $\mathrm{O} 1$ s stand for $-\mathrm{C}=\mathrm{O}, \mathrm{C}-\mathrm{O}$, and $-\mathrm{O}-$ $\mathrm{H}$ bonds [30]. However, it is essential to point out the N1s spectra at $400 \mathrm{eV}$ for the BP sample. The inset of Fig. 3c shows two predominant peaks around $400.3 \mathrm{eV}$ and 401.5 $\mathrm{eV}$, which can be assigned to $\mathrm{N}-\mathrm{H} / \mathrm{N}-\mathrm{O}$ and $\mathrm{C}-\mathrm{N}$ bonds, respectively. This result is 
directly associated with the residue of the PANF in the BP structure, as evidenced by SEM in Fig. 2c-d. As discussed in our previous work [27], after the dissolution of PANF by DMF solvent the BP showed tunnels (channels) spread over the CNT network, which can facilitate the impregnation of the buckypaper by epoxy resin during the preparation of the laminates. In addition, as presented in Fig. 3d by EDS image, there are traces of nitrogen in the BP sample (3.89 wt\%), which confirms the residual amount of PANF in the CNT film structure.
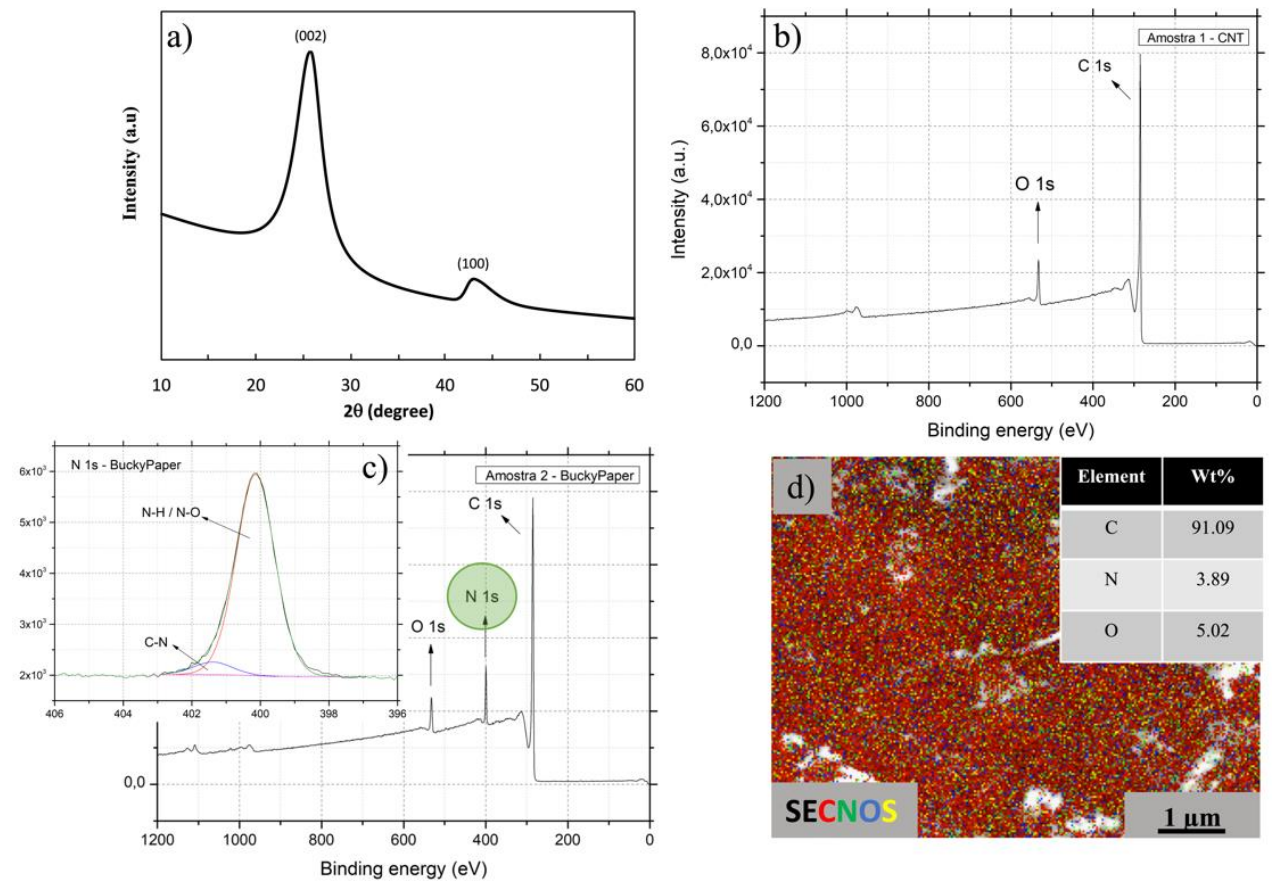

Fig. 3 XRD pattern of MWCNT (a), XPS spectra of MWCNT (b) and BP (c), and EDS image of the buckypaper (d).

\subsection{Electrical conductivity (DC) and EMI SE of the buckypaper}

As widely discussed by several authors [31-35], the shielding performance is directly associated with the electrical properties of the material. The electrical conductivity of the BP measured in this work was $1982 \mathrm{~S} / \mathrm{m}$ with a density of $0.29 \mathrm{~g} / \mathrm{cm}^{3}$, which is slightly lower than other BP works available in the literature. For instance, Lu et al. [23] prepared vacuum filtered MWCNT-BP with a density of $0.76 \mathrm{~g} / \mathrm{cm}^{3}$ and reached an electrical conductivity of $3300 \mathrm{~S} / \mathrm{m}$, whereas Hu and co-workers [36] obtained MWCNT-BP with 
density and conductivity of $0.45 \mathrm{~g} / \mathrm{cm}^{3}$ and $3800 \mathrm{~S} / \mathrm{m}$, respectively. The electrical conductivity of the BP is directly associated with the network formed by physical entanglement of the tubes. The interconnected structure may offer charge carrier channels providing innumerous conductive pathways in the $\mathrm{BP}$, which results in high electrical conductivity [37]. However, the use of PANF obstructs the dense network of the buckypaper (Fig 2d) and consequently results in a lower density of the BP, thus reducing the formed conductive pathways and the electrical conductivity of the CNT film. Moreover, it is important to mention that PANF residual mass present in the buckypaper network, especially between the tube's contacts, impacted the lower electrical properties obtained in this work. As detailed in our previous work [27], the residual mass of PANF after the removing process possibly isolated the contacts between the tubes, thus decreasing the electrical conductivity of the prepared buckypaper.

The power balance of the BP can be studied from the scattering parameters, $S_{\mathrm{ij}}$, which define the shielding efficiency of the material in terms of reflection $(\mathrm{R})$ and transmission (T) coefficients $[38,39]$. The absorption coefficient (A) can be calculated from $\mathrm{R}$ and $\mathrm{T}$ for any incident EM wave, as follows:

$$
A=1-R-T
$$

Where: $R=\left|S_{11}\right|^{2}$ and $T=\left|S_{21}\right|^{2}$.

Fig. 4a shows the power balance (transmission, reflection, and absorption coefficients) as a function of frequency for the prepared buckypaper. As can be seen, all the calculated parameters are almost constant over the frequency range, so that $77 \%$ of the incident EM wave was reflected. The reflected power can be associated with the electrical conductivity of the shielding material that generates an impedance mismatch between air/BP. Also, as discussed by Wu and collaborators [40], the small diameter and the high surface area of the tubes facilitates the reflection of the EM waves, so that a more 
reflective surface occurs. On the other hand, the polarization created among tube-tube contacts arouses losses in the BP, revealing an absorption coefficient (A) of 0.19 . Furthermore, the transmitted fraction of the EM wave power is close 0.05 , which can be attributed to the porosity of the CNT film, as previously shown by SEM in Fig. 2d.

EMI shielding effectiveness can be clarified in which the propagating EM wave is blocked by employing conductive materials [41,42]. The total shielding effectiveness $\left(\mathrm{SE}_{\mathrm{T}}\right)$ can be express in terms of the transmitted and reflected power of the EM wave, as demonstrated by Equation 3:

$$
S E_{T}=10 \log \left(\frac{P_{\text {input }}}{P_{\text {output }}}\right)
$$

where: $\mathrm{P}_{\text {input }}$ and $\mathrm{P}_{\text {output }}$ are the power of the incident and transmitted EM waves, respectively. When the EM wave interacts with a reflection shield, reflection, absorption, and multiple reflections can occur simultaneously [43]. Therefore, the total shielding effectiveness can be expressed by three main components: the primary reflection of the wave $\left(\mathrm{SE}_{\mathrm{R}}\right)$, internal absorption $\left(\mathrm{SE}_{\mathrm{A}}\right)$ and, secondary multiple reflections $\left(\mathrm{SE}_{\mathrm{M}}\right)$ inside the shielding material $[43,44]$. The $\mathrm{SE}_{\mathrm{T}}$ can be written as follows:

$$
S E_{T}(d B)=S E_{R}+S E_{A}+S E_{M}
$$

where:

$$
\begin{aligned}
& \mathrm{SE}_{\mathrm{R}}=-10 \log \left(1-\mathrm{S}_{11}{ }^{2}\right) \\
& \mathrm{SE}_{\mathrm{A}}=-10 \log \left(\frac{\mathrm{S}_{21}{ }^{2}}{1-\mathrm{S}_{11}{ }^{2}}\right) \text {, and } \\
& \mathrm{SE}_{\mathrm{M}}(\mathrm{dB})=-20 \log \left(1-10^{-\left(\mathrm{SE}_{A} / 10\right)}\right) .
\end{aligned}
$$

Figure $4 \mathrm{~b}$ shows the total shielding efficiency of the buckypaper. As can be seen, the SET is $\sim 22 \mathrm{~dB}$, which means that the buckypaper blocks more than $99 \%$ of the incident EM wave. Also, the EMI result is in the range required for computers and electronic 
devices [45]. Compared to other works available in the literature, the EMI performance of the buckypaper prepared here is below average. Hu et al. [36] achieved an EMI SE of $31.2 \mathrm{~dB}$, whereas $\mathrm{Wu}$ and coworkers [40] presented a super high EMI SE of 61-67 dB for the CNT film. The EMI performance obtained in this work can be attributed to the lower electrical conductivity and density of the $\mathrm{BP}$, respectively. Also, the analysis of the density of the buckypaper demands special attention here. For instance, Zhang et al. [46] prepared both solid and foam $\mathrm{PMMA} / \mathrm{Fe}_{3} \mathrm{O}_{4} @ \mathrm{MWCNT}$ nanocomposites with densities of 1.25 and $0.38 \mathrm{~g} / \mathrm{cm}^{3}$, respectively. The solid composite presented an EMI SE of around $25 \mathrm{~dB}$, and the latter showed a reduction to $13 \mathrm{~dB}$, which confirms the importance of the density in the EMI SE properties of the composites. In this work, the density of the CNT film was $0.29 \mathrm{~g} / \mathrm{cm}^{3}$, a lower value than that obtained by $\mathrm{Wu}\left(0.45 \mathrm{~g} / \mathrm{cm}^{3}\right)$. The importance of the shielding values at such low density could be more appropriately described in terms of specific EMI SE (EMI SE divided by density). The highly porous buckypaper prepared in this work displays the specific EMI SE value of $76 \mathrm{~dB} . \mathrm{cm}^{3} / \mathrm{g}$, which is similar to other buckypaper studies described above, and highly superior compared to the most common shielding materials available in the literature [47-49].

To have a full understanding of the shielding mechanism of the BP reflection, absorption, and multiple reflections need to be considered carefully. $\mathrm{SE}_{\mathrm{R}}$ and $\mathrm{SE}_{\mathrm{A}}$ components were calculated according to Equation 4 and plotted in Fig. 4b. As can be seen, $S E_{R}$ values range around $8.4 \mathrm{~dB}$, which is considered a relevant fraction of the total EMI SE ( 22 dB). The CNT film has mobile charge carriers with great mobility that interact with the incident EM waves. The highly dense CNT network that forms the BP provides the innumerous paths to transport the mass of electrons freely, resulting in a favorable conductive interface between the tubes, and consequently, more interactions with the incident EM waves are created, improving the $\mathrm{SE}_{\mathrm{R}}$ and the total EMI SE values 
[50]. Moreover, it is worth mentioning that the impedance of the conductive materials is small compared to the free space, resulting in a high impedance mismatch that conducts to reflective behavior of the incident waves [36]. The absorption component plays a crucial role in shielding properties of the $\mathrm{BP}$, once the $\mathrm{SE}_{\mathrm{A}}$ was superior to $\mathrm{SE}_{\mathrm{R}}$, showing a value around $13.6 \mathrm{~dB}$. The mechanisms related to the absorption are associated with the MWCNT entangled network of the buckypaper. The interaction of the high-frequency EM waves can stimulate delocalized $\square$-electrons of MWCNT for migrating, tunneling, and hopping mechanisms, which result in high ohmic loss and the conversion of the EM energy into heat [51]. Furthermore, when EM waves impinge on BP's surface, the polarization process in the MWCNT network will lead to polarization losses [52]. The combination of these two factors was beneficial to enhance the absorption of the CNT film. It is important to point out that the multiple reflections had a minor contribution to the EMI SE properties of the buckypaper. The porous structure of the film scattered and reflected the entered EM waves several times convert them into heat and, consequently, contributing to improving the shielding properties of the buckypaper. Fig. $4 \mathrm{c}$ presents the schematic diagram of the EM shielding mechanism of the buckypaper.

The skin depth $(\square)$ can be used to clarify the ability of BP to block electromagnetic waves. High-frequency EM waves only penetrate near the surface region of shielding material. This phenomenon is known as skin effect, and the field drops exponentially with depth [53]. The depth at which drops to 1/e ( $e$ is the Neper number) of the incident value can be expressed as follows:

$$
\delta=\left(\sqrt{\pi f \mu \sigma_{T}}\right)^{-1}
$$

where: $f, \mu, t$, and $\sigma_{T}$ are the wave frequency, permeability, thickness, and total electrical conductivity of the shielding material, respectively. Skin depth is one of the most important parameters of EMI study due to the absorption features of the shielding 
material. As can be seen, $\square$ decreases with increasing frequency (Fig. 4d) and ranged from 0.11 to $0.09 \mathrm{~mm}$. Interestingly, the $\square$ values greater than the thickness of the BP. According to Equation 5, the skin depth decreases with increasing conductivity; thus, it was expected that the use of carbon nanotube with high electrical conductivity would result in lower values of $\square$ and high EMI SE performance. However, as already discussed in this work, the measured conductivity of the buckypaper was below the average conductivity of other works available in the literature. Hence, the use of PANF during the preparation of the buckypaper was twofold. On the one hand, it provided great flexibility to the CNT film, making the lamination process of the composites easier but on the other hand, the residual mass of PANF in the CNT network and the cavities and channels formed after the dissolution of the nanofibers reduced the electrical conductivity of the BP, affecting the EMI SE properties detrimentally and, consequently, increasing the skin depth.
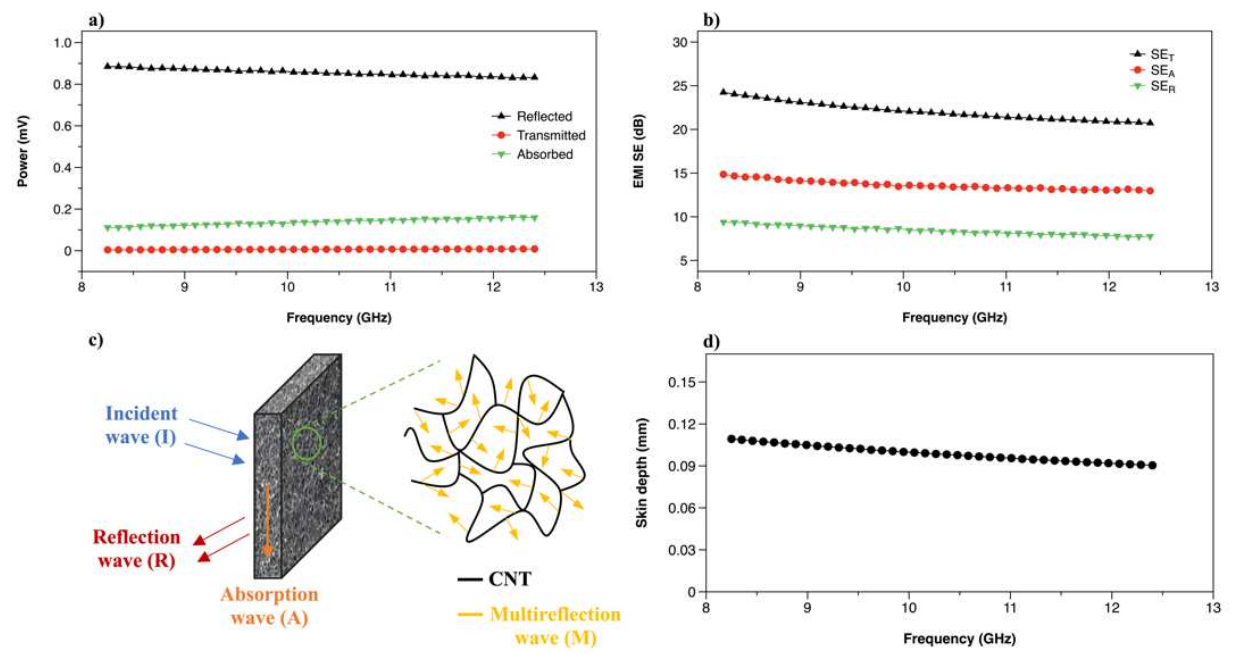

Fig. 4 Power balance (a), EMI SE (b), shielding mechanism (c), and skin depth (d) of the prepared buckypaper.

\subsection{Power balance of GF/EP/BP composites}

The GF/EP/BP composites with several configurations, as schematized in Fig. 1, were prepared by hot press from the stacking of GF/EP layers and BP films. Fig. 5(a-f) 
shows the reflection, absorption, and transmission coefficients for all BP composites prepared in the X-band frequency. As can be seen, for configuration 100 almost $90 \%$ of the EM wave power was reflected, $10 \%$ was absorbed, and 1-2\% transmitted. It is important to point out that all three coefficients were nearly constant over the frequency range. The incorporation of one more BP film (configuration 110) led to similar results; however, small differences could be detected in Fig. 5b. Firstly, the reflected power presented a slight decrease ( $\mathrm{R} \sim 80 \%$ ), whereas the absorption coefficient increase for values around $0.15-0.20$. Also, both power coefficients presented small fluctuations over the frequency range, particularly from 11 to $12.4 \mathrm{GHz}$, showing a little improvement of the absorption power. Fig. 5(c-d) displayed the most unusual power balance results of all composite samples. For sample 001, the reflection coefficient presented a strong descending behavior varying from 0.8 to 0.46 , whereas absorption power rapidly raised over the frequency range (from 0.18 to 0.50 ), which suggests an adequate absorption capacity of the sample. Configuration 011 presented a more robust absorption capacity of all studied samples, showing that $98 \%$ of the EM power was absorbed in $10.5-11$ $\mathrm{GHz}$, and the reflection coefficient dropped near to zero at the same frequency range. Samples 101 and 111 showed very similar power balance results, as can be visualized in Fig. 5(e-f). It can be found that around $98 \%$ of the incident EM power was reflected, and absorption and transmitted coefficients were close to zero. It is essential to point out that the ultra-low $\mathrm{T}\left(<10^{-5}\right)$ indicates that both configurations may possess excellent EM shielding performance. 

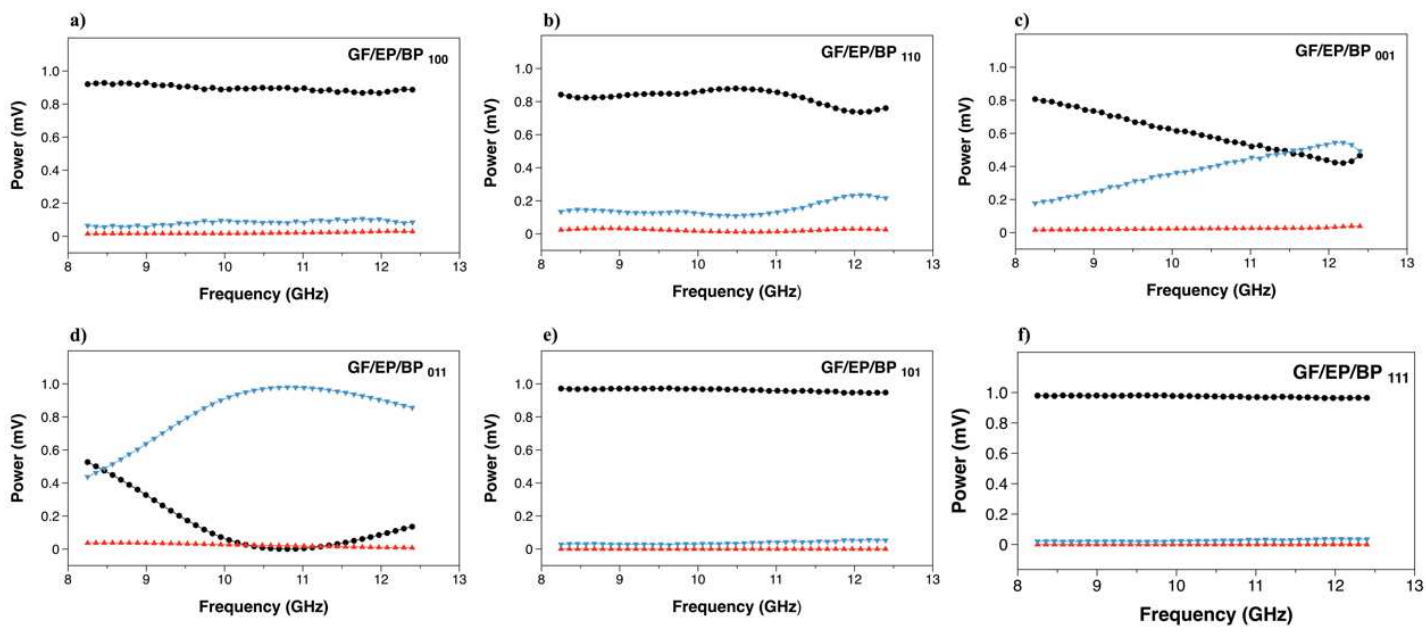

Fig. 5 Power balance (reflection, transmission, and absorption components) of all composite samples over the X-band.

\subsection{EMI SE of GF/EP/BP composites}

Generally, EMI SE results are closely associated with electrical conductivity, i.e., highly conductor materials will provide excellent EMI performance. Fig. 6(a-c) shows the EMI results of the GF/EP/BP laminates in X-band. The EMI SE of 100 laminate reaches around $19 \mathrm{~dB}$, which was close to the target level of $20 \mathrm{~dB}$ required for commercial applications [54]. It is important to mention that the sample 110 showed very similar results, showing $\mathrm{SE}_{\mathrm{T}}$ values of around $19 \mathrm{~dB}$ as well. On the other hand, 011 (and 001) configuration presented a small decrease in shielding properties, achieving an EMI $\mathrm{SE}$ value of 16-17 $\mathrm{dB}$. Interestingly, the mentioned sample (Fig. 6b) presented an ascending shielding trend from 10 to $12.4 \mathrm{GHz}$, which contrasts with the previous selection that showed a tiny descending behavior over the X-band range. The most significant EMI results were presented by 101 and 111 laminates, as can be seen in Fig. 6c. Both samples reached promising EMI performance of around 50-60 dB, with a small advantage for the later, which means at least $99.999 \%$ of the incident EM wave is blocked by both composite samples. 
To fully understand the shielding mechanism in the GF/EP/BP laminates, it is necessary to evaluate the absorption $\left(\mathrm{SE}_{\mathrm{A}}\right)$ and the reflection $\left(\mathrm{SE}_{\mathrm{R}}\right)$ components to the total shielding effectiveness. Moreover, it is crucial to clarify the role of the multiple internal reflections of the EM wave in the EMI properties of the composites. $\mathrm{SE}_{\mathrm{M}}$ is essential for porous materials, but it can be neglected in the case of a thick absorbing shield due to the high value of the $\mathrm{SE}_{\mathrm{A}}$. Therefore, for highly absorbing materials, when $\mathrm{SE}_{\mathrm{A}}>10 \mathrm{~dB} \mathrm{SE}_{\mathrm{M}}$ can be safely ignored [55]. Fig. 6d presents the $\mathrm{SE}_{\mathrm{A}}, \mathrm{SE}_{\mathrm{R}}$, and $\mathrm{SE}_{\mathrm{M}}$ for all samples prepared at $10 \mathrm{GHz}$. To further clarify the differences in the shielding properties, it is essential to study carefully how the buckypaper position in the composite can affect/change the shielding mechanism from reflection to absorption. In the first studied sample (100), most of the EM wave is reflected from the surface of the composite showing a $\mathrm{SE}_{\mathrm{A}} / \mathrm{SE}_{\mathrm{T}}$ ratio of 0.43 . This behavior can be attributed to the impedance mismatch between the shield (BP) and the air, which means the $\mathrm{SE}_{\mathrm{R}}$ is the dominant mechanism. A small modification in the position of the BP configuration (001) dramatically changed the shielding mechanism of the material. Although the EMI SE was close to both samples, the absorption mechanism dominated the shielding properties showing an improved $\mathrm{SE}_{\mathrm{A}} / \mathrm{SE}_{\mathrm{T}}$ ratio of 0.75 . This behavior can be attributed to the interfacial polarization in which the accumulation of charges at the GF/EP/BP interfaces contributes to improving the conductivity so that the EMI shielding performance is boosted via absorption shielding mechanism [56]. The incorporation of a second buckypaper layer in the mid-plane of the composite revealed an improvement towards absorption for both composite samples (110 and 011). As can be found, GF/EP/BP 110 composite enhanced its $\mathrm{SE}_{\mathrm{A}} / \mathrm{SE}_{\mathrm{T}}$ to 0.49 , whereas $\mathrm{SE}_{\mathrm{A}}$ dominated at least $97 \%$ of the total shielding for 011 configuration at $10 \mathrm{GHz}$. In the latter configuration, the EM waves can penetrate more easily in the sample; in other words, less EM waves are reflected on the 
surface of the piece. Besides, the incident waves are trapped in a highly porous structure, which enhances the multiple reflections and prevents them from escaping from the sample. As a result, the 011 composite exhibited lower $\mathrm{SE}_{\mathrm{R}}$ values compared to 110 laminate. The last group of samples (101 and 111) presented the highest EMI SE values for all the configurations studied in this work, with a dominant absorption shielding mechanism. However, it is important to point out that the absorption component of the sample $\mathrm{GF} / \mathrm{EP} / \mathrm{BP}_{101}$ had a strong dependence on the insulating layer, showing higher EMI results than 111 configuration at high frequencies. Fig. $6 \mathrm{c}$ showed that $\mathrm{SE}_{\mathrm{R}}$ for both samples was practically the same over the $\mathrm{X}$-band, whereas $\mathrm{SE}_{\mathrm{A} 101}$ was higher than $\mathrm{SE}_{\mathrm{A} 111}$ from 11-12 GHz. The introduction of two wave-transmitting layers of $1.5 \mathrm{~mm}$ $\left(\mathrm{GF} / \mathrm{EP} / \mathrm{BP}_{111}\right)$ enhanced the $\mathrm{SE}_{\mathrm{A}}$ value to $37 \mathrm{~dB}$ over the studied frequency range. As already discussed in this work, the EM waves were possibly confined within the porous structure of the BP, which avoided them from escaping from the sample, thus enhancing the absorption performance of the composite. On the other hand, the introduction of one wave-transmitting layer of $3.0 \mathrm{~mm}\left(\mathrm{GF} / \mathrm{EP} / \mathrm{BP}_{101}\right)$ initially reduced the SE performance of the material, but for frequencies from 11-12 GHz, an apparent peak was observed followed by ascending of absorption performance. This phenomenon suggests that the increase of $\mathrm{SE}_{\mathrm{A}}$ by increasing the wave-transmitting layer can be associated with the constructive interference of the reflected electromagnetic waves in phase since they were absorbed by the BP structure and dissipated as heat. As discussed in the literature $[36,45]$, the EM waves can be reflected several times between two BP layers, which leads to an enhancement of the shielding performance due to the constructive interference of the reflected EM waves in phase. The EMI SE values of $\mathrm{GF} / \mathrm{EP} / \mathrm{BP}_{101}$ composite can reach $77 \mathrm{~dB}$ at $11.9 \mathrm{GHz}$, showing a more robust shielding capacity. 

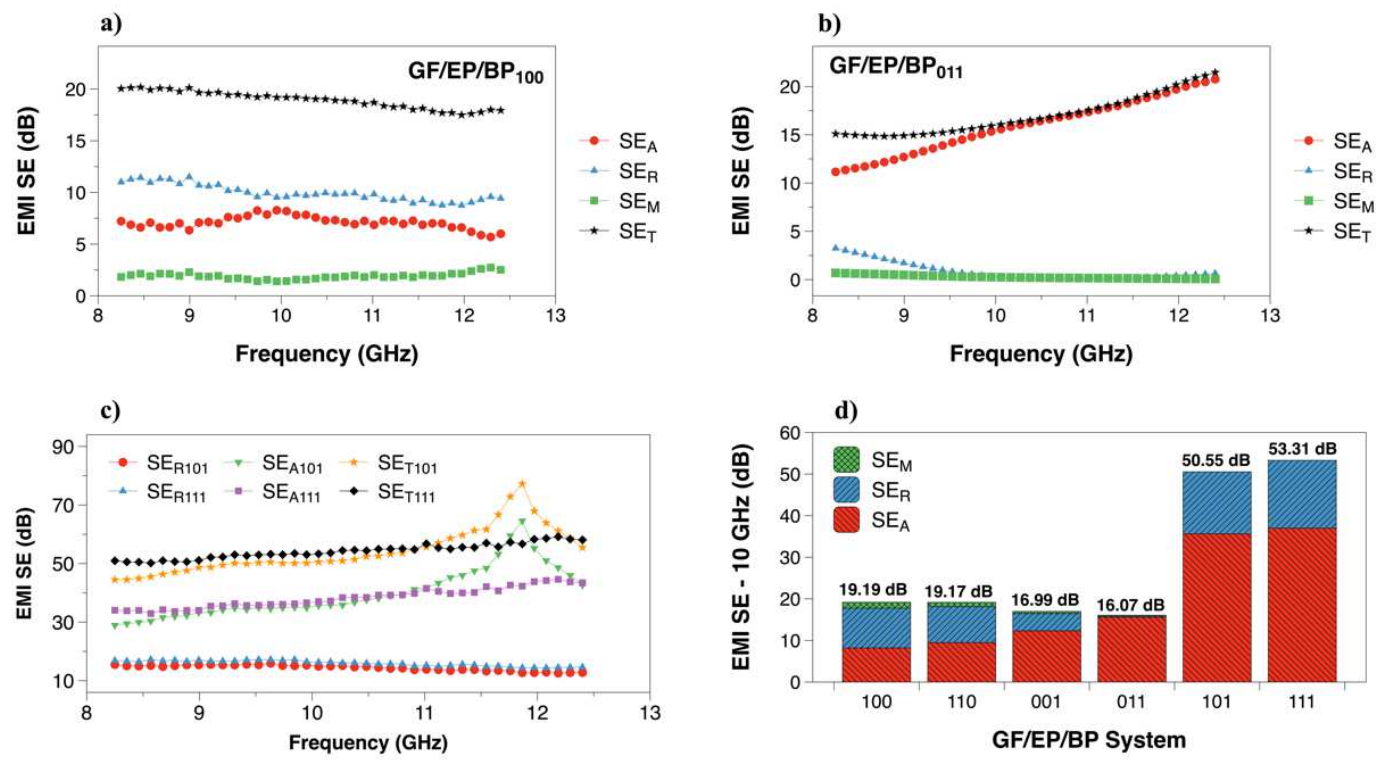

Fig. 6 EMI SE of GF/EP/BP composites for 100 (a), 011 (b), 111 (c) and $\mathrm{SE}_{\mathrm{A}}, \mathrm{SE}_{\mathrm{R}}, \mathrm{SE}_{\mathrm{M}}$ at the frequency of $10 \mathrm{GHz}(\mathrm{d})$ for all studied samples.

\subsection{Electrical conductivity, skin depth, and attenuation constant of GF/EP/BP composites}

As widely discussed in this work, the electrical conductivity has a significant contribution to the EMI SE results. Thus, the total electrical conductivity ( $\square$ ) should be carefully investigated in order to have a better comprehension of the shielding properties of the BP composites. The $\square$ is composed of a frequency-dependent (AC) and independent (DC) components, as demonstrated by Equations 6 and 7:

$$
\begin{gathered}
\sigma=\sigma_{A C}+\sigma_{D C} \\
\sigma_{A C}=2 \pi f \varepsilon_{0} \varepsilon^{\prime \prime}
\end{gathered}
$$

where: $f$ is the frequency $(\mathrm{Hz})$, and $\square_{0}$ is the permittivity of the free space $\left(\square_{0}=8.854 \mathrm{x}\right.$ $10^{-12} \mathrm{~F} / \mathrm{m}$ ). Fig. 7 a shows the $\mathrm{DC}$ and $\mathrm{AC}$ (at $8.25 \mathrm{GHz}$ ) conductivities for all $\mathrm{BP}$ composites studied in this work. As clearly seen, $\square_{A C}$ presents a major contribution to the samples' total conductivity, which is one of the reasons for improving EMI SE results. However, it is important to add that $\square_{A C}$ is directly affected by the permittivity of the 
samples. Permittivity is a crucial parameter to understand the mechanism of microwave absorption, and it can be described as follows:

$$
\varepsilon_{r}=\varepsilon^{\prime}-j \varepsilon^{\prime \prime}
$$

where $\varepsilon^{\prime}$ and $\varepsilon^{\prime \prime}$ are the real and the imaginary components of permittivity. The real permittivity describes the electric energy storage, and the imaginary part represents the dielectric losses due to relaxation and polarization, resulting in the dissipation of microwaves as heat [57]. Thus, it is possible to deduce that the incorporation of the BP layers enhanced the dielectric losses of the samples, improving the electrical conductivity, and consequently, the shielding properties of the composites. Also, the mechanisms that explain the dielectric losses in BP composites should be investigated carefully. The interface between the buckypaper, epoxy, and glass fibers are responsible for interfacial polarization, which contributes to dielectric losses. Since BP and EP/GF layers possess different dielectric properties, the accumulation of charges at the interface will likely occur, which improves the conductivity of the samples. Such polarization contributes to the improvement of shielding performance via a secondary shielding mechanism (absorption) [58,59].

Fig. $7 \mathrm{~b}$ shows the skin depth $(\square)$ and the attenuation constant $(\square)$ for all studied composites. Interestingly, $\square$ decreases with increasing $\square$, which can be associated with the large concentration of charge carriers, which possibly made easy the interaction with the incident EM at the composite interface. As already discussed in this work, an enhancement in the conductivity will result in strong EMI performance. The attenuation constant also provides valuable information about the capability of the composite to attenuate microwave radiation, as demonstrated by Equation 9 [60]:

$$
\alpha=\frac{\sqrt{2} \pi f}{c} \sqrt{\left(\mu^{\prime \prime} \varepsilon^{\prime \prime}-\mu^{\prime} \varepsilon^{\prime}\right)+\sqrt{\left(\mu^{\prime \prime} \varepsilon^{\prime \prime}-\mu^{\prime} \varepsilon^{\prime}\right)^{2}+\left(\mu^{\prime} \varepsilon^{\prime \prime}-\mu^{\prime \prime} \varepsilon^{\prime}\right)^{2}}}
$$


Where: $f$ is the frequency, $c$ is the velocity of the EM in the free space, $\mu^{\prime}$ and $\mu^{\prime \prime}$ are the real and the imaginary components of permeability. As can be seen, 101 and 111 showed the highest attenuation constant, corresponding thus to the ideal attenuation effect for the incident EM wave. However, caution should be paid here. Poor absorption capacity can occur as a result of both high and low electrical conductivity. Also, high permittivity values are not ideal for the impedance matching, once more reflections of the wave would be present on the surface of the material, which would conduct a reduced absorption capacity. In this work, a highly porous carbon nanotube buckypaper, a conductive material, was incorporated in glass fiber reinforced epoxy composites (electrically isolating material). The combination of both conducted to an optimized conductivity, improved impedance matching, and hence high microwave capacity.

Table 1. Electrical conductivity (AC and DC), skin depth, and the attenuation constant of all BP composites.

\begin{tabular}{ccccc}
\hline Composite System & $\square_{\mathrm{DC}}(\mathbf{S} / \mathbf{m})$ & $\square_{\mathrm{AC}}{ }^{*}(\mathbf{S} / \mathbf{m})$ & $\square^{*}(\mathbf{m m})$ & $\square^{*}$ \\
\hline Sample 100 & 11.73 & 4.88 & 1.25 & 688.03 \\
Sample 110 & 15.13 & 4.76 & 1.11 & 757.66 \\
Sample 001 & 8.64 & 7.09 & 2.08 & 554.41 \\
Sample 011 & 9.37 & 6.66 & 2.15 & 448.91 \\
Sample 101 & 21.49 & 19.05 & 1.04 & 917.66 \\
Sample 111 & 29.92 & 25.26 & 0.83 & 1230.62 \\
\hline * measured at 10 GHz & & & & \\
\hline
\end{tabular}

\subsection{Reflection loss of GF/EP/BP composites}

The microwave properties of the GF/EP/BP laminates can be evaluated by the reflection loss (RL) based on the metal back-panel and the generalized transmission line theory. RL value can be calculated using complex electromagnetic parameters and the absorber thickness by the following equations $[61,62]$ : 


$$
\begin{gathered}
R L(d B)=20 \log \left|\frac{Z_{i n}-Z_{0}}{Z_{i n}+Z_{0}}\right| \\
Z_{0}=\sqrt{\frac{\mu_{0}}{\varepsilon_{0}}} \\
Z_{\text {in }}=Z_{0} \sqrt{\frac{\mu_{r}}{\varepsilon_{r}}} \tanh \left[j\left(\frac{2 \pi f d}{c}\right)\right] \sqrt{\mu_{r} \varepsilon_{r}}
\end{gathered}
$$

where: $Z_{\text {in }}$ is the input characteristic impedance, $Z_{0}$ is the characteristic impedance of the free space, $\mu_{0}$ is the permeability of the free space, $\varepsilon_{0}$ is the dielectric constant free space, $c$ is the velocity of light, $\varepsilon_{r}$, and $\mu_{r}$ are the relative permittivity and permeability, respectively. The RL curves as a function of the frequency of GF/EP/BP composites over the X-band (8.2-12.4 GHz) are presented in Fig. 7a. It can be found that the microwave absorption properties can be manipulated by changing the BP position in the laminate (in other words, varying the thickness of the wave-transmitting layer) and the number of the CNT films inserted between the GF/EP prepreg. Obviously, only GF/EP/BP 110 sample displays strong attenuation performance, revealing a minimum RL value of $-21.16 \mathrm{~dB}$ at 10.37 GHz, which means $99 \%$ of the incident EM wave was attenuated. Also, the absorption bandwidth with reflection loss below $-10 \mathrm{~dB}$ was $2.76 \mathrm{GHz}$ (from 9.21 to $11.97 \mathrm{GHz}$ ). The improved attenuation capacity of the $\mathrm{GF} / \mathrm{EP} / \mathrm{BP}_{110}$ sample can be ascribed to the impedance match condition. According to Equations 11 and 12, the ideal impedance matching condition is achieved when the $\frac{Z_{\text {in }}}{Z_{0}}$ condition get closer to 1 , which indicates all the incident EM waves can enter into the material and be absorbed. From the reflection loss curves, it is clear that $\mathrm{GF} / \mathrm{EP} / \mathrm{BP}_{110}$ had better impedance matching than the other samples, which suggests that the attenuation performance is strongly dependent on their electrical conductivity. As previously discussed in this work, high conductivity values will conduct more reflections of the EM wave on the surface of the composite resulting in poor attenuation behavior. Although the $\mathrm{GF} / \mathrm{EP} / \mathrm{BP}_{110}$ sample had presented the one of the highest total conductivity results, it was favorable to achieve the ideal 
impedance matching, showing adequate conductivity values, revealing thus strong absorbing properties.

Fig. 7(b-c) compares simulated and experimental results of $\mathrm{GF} / \mathrm{EP} / \mathrm{BP}_{110}$ composite in the frequency range of $8.2-12.4 \mathrm{GHz}$. In addition to experimental work, a computational simulation study was carried out for comparative work, aiming to design a robust absorbing material with a smaller thickness possible. The ideal thickness and the wave-transmitting layer of the composite were calculated through a commercial microwave software, FEKO ${ }^{\circledR}$, based on the complex parameters $\left(\mu_{r}\right.$ and $\left.\varepsilon_{r}\right)$ of BP and $\mathrm{GF} / \mathrm{EP}$ composite. The simulation results revealed a maximum RL value of $-20.36 \mathrm{~dB}$ at the frequency of $9.74 \mathrm{GHz}$ with $-10 \mathrm{~dB}$ absorption bandwidth of $3.04 \mathrm{GHz}$. By comparing the simulation and experimental results, a small discrepancy can be observed since the thickness and the wave-transmitting layer were slightly different, which suggests the $\mathrm{GF} / \mathrm{EP} / \mathrm{BP}_{110}$ composite was well-designed to have high EM wave absorbing performance.
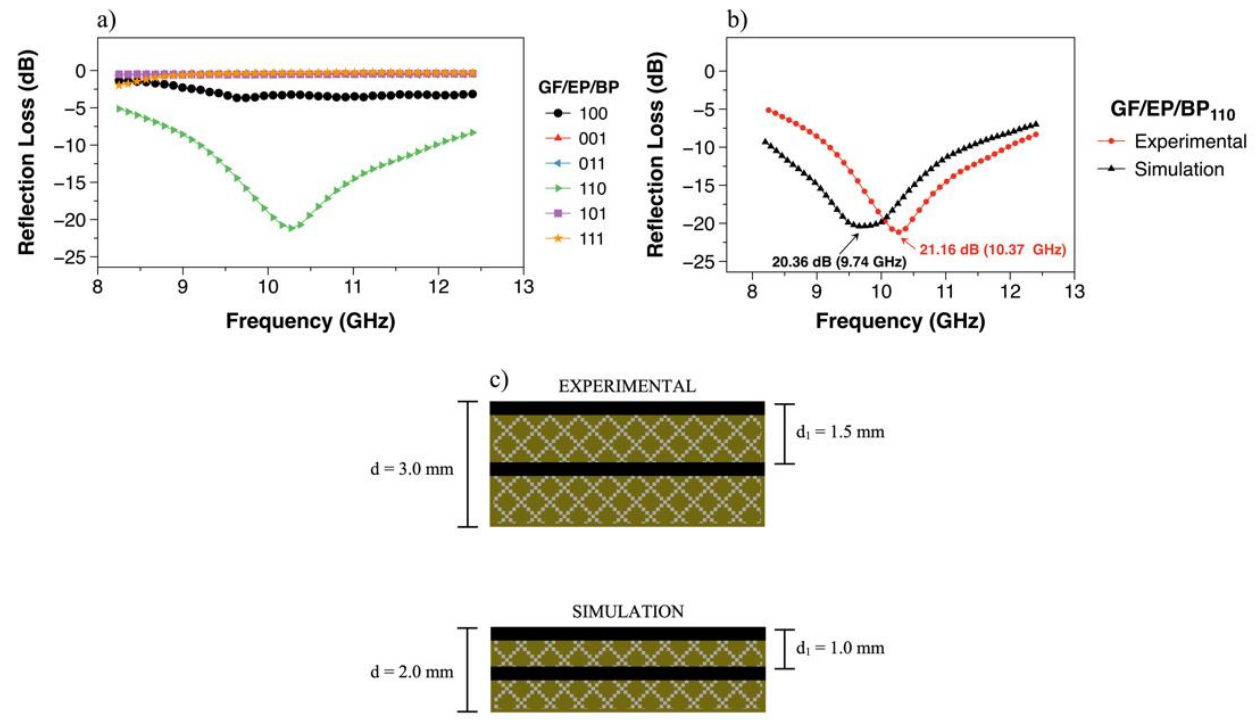

Fig. 7 Reflection loss of all studied GF/EP/BP composites (a). Comparison between simulation and experimental results (b) configurations and dimensions (c) of GF/EP/BP 110 laminate. 


\section{Conclusions}

Multi-walled carbon nanotube buckypaper was prepared by vacuum filtration showing great flexibility, low density $\left(0.29 \mathrm{~g} / \mathrm{cm}^{3}\right)$, and adequate conductivity. The correspondent EMI SE of the buckypaper was $\sim 22 \mathrm{~dB}$, whereas the specific EMI SE was as high as $76 \mathrm{~dB} \cdot \mathrm{cm}^{3} / \mathrm{g}$ in the X-band. The CNT film was incorporated between the GF/EP layers, and the laminate was cured in a hot press machine. Six different architectures were proposed in this work based on the number of the BP inserted and the length of the wavetransmitting layer of the composite. $\mathrm{GF} / \mathrm{EP} / \mathrm{BP}_{111}$ and $\mathrm{GF} / \mathrm{EP} / \mathrm{BP}_{101}$ composites presented a remarkable EMI shielding performance of around 50-60 dB, representing that $99.999 \%$ of the EM wave could be blocked. Also, the later sample surpassed this capacity reaching $77 \mathrm{~dB}$ in the high frequencies $(11-12 \mathrm{GHz}) . \mathrm{GF} / \mathrm{EP} / \mathrm{BP}_{110}$ laminate showed the most exciting results being applied both as shielding and absorbing material. The mentioned sample achieved an EMI SE of 19.17, dB which satisfies the shielding level ( $20 \mathrm{~dB})$ for commercial applications, and reached a minimum RL value of $-21.36 \mathrm{~dB}$, which qualifies it to be used as a robust absorbing material. Based on the detailed study carried out in this work, it can be concluded that GF/EP/BP composites are suitable for both shielding and absorbing demands, providing some advantages such as lightweight, a simple manufacturing process, and multifunctional characteristics for applications in electronics and aerospace.

\section{Acknowledgments}

The authors would like to thank the financial support received from the Brazilian Funding Institutions: FAPESP (Fundação de Amparo à Pesquisa do Estado de São Paulo) (2017/04740-0 and 2018/09531-2), CAPES (Coordenação de Aperfeiçoamento de Pessoal de Nível Superior) - Finance Code 001, and CNPq (Conselho Nacional de Desenvolvimento Científico e Tecnológico) (305123/2018-1). 


\section{References}

1. B. Zhao, S. Wang, C. Zhao, R. Li, S. M. Hamidinejad, Y. Kazemi, and C. B. Park, Carbon N. Y. 127, 469 (2018).

2. J. Abraham, M. Arif P, P. Xavier, S. Bose, S. C. George, N. Kalarikkal, and S. Thomas, Polymer (Guildf). 112, 102 (2017).

3. Z. Liu, Y. Lv, J. Fang, X. Zuo, C. Zhang, and X. Yue, Compos. Part B Eng. 155, 148 (2018).

4. R. Baan, Y. Grosse, B. Lauby-Secretan, F. El Ghissassi, V. Bouvard, L. BenbrahimTallaa, N. Guha, F. Islami, L. Galichet, and K. Straif, Lancet Oncol. 12, 624 (2011).

5. J. Grellier, P. Ravazzani, and E. Cardis, Environ. Int. 62, 55 (2014).

6. X. Liu, L. Zhang, X. Yin, F. Ye, Y. Liu, and L. Cheng, Mater. Des. 104, 68 (2016).

7. F. Meng, H. Wang, F. Huang, Y. Guo, Z. Wang, D. Hui, and Z. Zhou, Compos. Part B Eng. 137, 260 (2018).

8. N. Mattiucci, M. J. Bloemer, N. Aközbek, and G. D’Aguanno, Sci. Rep. 3, 3203 (2013).

9. A. Kumar, V. Agarwala, and D. Singh, Adv. Powder Technol. 25, 483 (2014).

10. S. Rana, S. Parveen, and R. Fangueiro, in edited by S. Rana and R. B. T.-A. C. M. for

A. E. Fangueiro (Woodhead Publishing, 2016), pp. 265-293.

11. X. Jia, J. Wang, X. Zhu, T. Wang, F. Yang, W. Dong, G. Wang, H. Yang, and F. Wei, J. Alloys Compd. 697, 138 (2017).

12. J. Yang, X. Liao, J. Li, G. He, Y. Zhang, W. Tang, G. Wang, and G. Li, Compos. Sci. Technol. 181, 107670 (2019).

13. H. Wei, X. Yin, X. Li, M. Li, X. Dang, L. Zhang, and L. Cheng, Carbon N. Y. 147, 276 (2019).

14. M. H. Al-Saleh, W. H. Saadeh, and U. Sundararaj, Carbon N. Y. 60, 146 (2013).

15. I. W. Nam, H. K. Lee, and J. H. Jang, Compos. Part A Appl. Sci. Manuf. 42, 1110 (2011).

16. H.-Y. Wu, L.-C. Jia, D.-X. Yan, J. Gao, X.-P. Zhang, P.-G. Ren, and Z.-M. Li, Compos. Sci. Technol. 156, 87 (2018).

17. B. Ribeiro, E. C. Botelho, and M. L. Costa, Polimeros 25, 94 (2015).

18. Y. Huang, N. Li, Y. Ma, F. Du, F. Li, X. He, X. Lin, H. Gao, and Y. Chen, Carbon N. Y. 45, 1614 (2007).

19. W. Zhang, H. Xiong, S. Wang, M. Li, and Y. Gu, Chinese J. Aeronaut. 28, 1245 (2015).

20. G. T. Pham, Y.-B. Park, S. Wang, Z. Liang, B. Wang, C. Zhang, P. Funchess, and L. Kramer, Nanotechnology 19, 325705 (2008).

21. A. M. Díez-Pascual, J. Guan, B. Simard, and M. A. Gómez-Fatou, Compos. Part A Appl. Sci. Manuf. 43, 1007 (2012).

22. J. H. Han, H. Zhang, P. F. Chu, A. Imani, and Z. Zhang, Compos. Sci. Technol. 114, 1 (2015).

23. S. Lu, J. Shao, K. Ma, X. Wang, L. Zhang, and Q. Meng, J. Phys. D. Appl. Phys. 49, 445308 (2016).

24. Q. Xia, Z. Zhang, H. Chu, Y. Liu, and J. Leng, Compos. Part A Appl. Sci. Manuf. 113, 132 (2018).

25. Z. P. Wu, T. Liu, D. M. Chen, G. Wu, Q. H. Wang, Y. H. Yin, Y. S. Li, Q. F. Xu, and A. Krishamurthy, RSC Adv. 6, 62485 (2016).

26. J. A. Rojas, L. A. Ardila-Rodríguez, M. F. Diniz, M. Gonçalves, B. Ribeiro, and M. C. Rezende, Mater. Des. 166, (2019).

27. J. A. Rojas, L. A. Ardila-Rodríguez, M. F. Diniz, M. Gonçalves, B. Ribeiro, and M.

C. Rezende, Heliyon 5, e01386 (2019). 
28. R. Ravindren, S. Mondal, K. Nath, and N. C. Das, Compos. Part A Appl. Sci. Manuf. 118, 75 (2019).

29. Y. Huangfu, K. Ruan, H. Qiu, Y. Lu, C. Liang, J. Kong, and J. Gu, Compos. Part A Appl. Sci. Manuf. 121, 265 (2019).

30. X. Fan, G. Zhang, J. Li, Z. Shang, H. Zhang, Q. Gao, J. Qin, and X. Shi, Compos. Part A Appl. Sci. Manuf. 121, 64 (2019).

31. H. Wang, K. Zheng, X. Zhang, T. Du, C. Xiao, X. Ding, C. Bao, L. Chen, and X. Tian, Compos. Part A Appl. Sci. Manuf. 90, 606 (2016).

32. S. Sankaran, K. Deshmukh, M. B. Ahamed, and S. K. Khadheer Pasha, Compos. Part A Appl. Sci. Manuf. 114, 49 (2018).

33. M. H. Al-Saleh and U. Sundararaj, Carbon N. Y. 47, 1738 (2009).

34. F. Kargar, Z. Barani, M. Balinskiy, A. S. Magana, J. S. Lewis, and A. A. Balandin, Adv. Electron. Mater. 5, 1800558 (2019).

35. Y. Zhang, Z. Yang, and B. Wen, Adv. Mater. Interfaces 6, 1900375 (2019).

36. Y. Hu, D. Li, L. Wu, J. Yang, X. Jian, and Y. Bin, Compos. Sci. Technol. 181, (2019).

37. A. Chaudhary, S. Kumari, R. Kumar, S. Teotia, B. P. Singh, A. P. Singh, S. K.

Dhawan, and S. R. Dhakate, ACS Appl. Mater. Interfaces 8, 10600 (2016).

38. B. P. Singh, Prasanta, V. Choudhary, P. Saini, S. Pande, V. N. Singh, and R. B. Mathur, J. Nanoparticle Res. 15, (2013).

39. A. P. Singh, M. Mishra, A. Chandra, and S. K. Dhawan, Nanotechnology 22, (2011). 40. Z. P. Wu, M. M. Li, Y. Y. Hu, Y. S. Li, Z. X. Wang, Y. H. Yin, Y. S. Chen, and X. Zhou, Scr. Mater. 64, 809 (2011).

41. N. Joseph, C. Janardhanan, and M. T. Sebastian, Compos. Sci. Technol. 101, 139 (2014).

42. N. Joseph, J. Varghese, and M. T. Sebastian, RSC Adv. 5, 20459 (2015).

43. S. Gupta and N.-H. Tai, Carbon N. Y. 152, 159 (2019).

44. M. Arjmand, M. Mahmoodi, G. A. Gelves, S. Park, and U. Sundararaj, Carbon N. Y. 49, 3430 (2011).

45. Y. Li, B. Shen, D. Yi, L. Zhang, W. Zhai, X. Wei, and W. Zheng, Compos. Sci. Technol. 138, 209 (2017).

46. H. Zhang, G. Zhang, J. Li, X. Fan, Z. Jing, J. Li, and X. Shi, Compos. Part A Appl. Sci. Manuf. 100, 128 (2017).

47. J. Li, G. Zhang, Z. Ma, X. Fan, X. Fan, J. Qin, and X. Shi, Compos. Sci. Technol. 129, 70 (2016).

48. H.-B. Zhang, Q. Yan, W.-G. Zheng, Z. He, and Z.-Z. Yu, ACS Appl. Mater. Interfaces 3, 918 (2011).

49. A. Ameli, M. Nofar, S. Wang, and C. B. Park, ACS Appl. Mater. Interfaces 6, 11091 (2014).

50. A. Kumar, A. P. Singh, S. Kumari, A. K. Srivastava, S. Bathula, S. K. Dhawan, P. K. Dutta, and A. Dhar, J. Mater. Chem. A 3, 13986 (2015).

51. L. Wang, X. Jia, Y. Li, F. Yang, L. Zhang, L. Liu, X. Ren, and H. Yang, J. Mater. Chem. A 2, 14940 (2014).

52. S. Lu, K. Ma, X. Wang, X. Xiong, W. Xu, and C. Jia, J. Appl. Polym. Sci. 132, (2015). 53. X. Liu, X. Yin, L. Kong, Q. Li, Y. Liu, W. Duan, L. Zhang, and L. Cheng, Carbon N. Y. 68, 501 (2014).

54. D. Feng, P. Liu, and Q. Wang, Compos. Part A Appl. Sci. Manuf. 124, 105463 (2019). 55. P. Saini and M. Aror, in New Polym. Spec. Appl. (InTech, 2012).

56. P. Verma, P. Saini, R. S. Malik, and V. Choudhary, Carbon N. Y. 89, 308 (2015).

57. T. H. Ting, Y. N. Jau, and R. P. Yu, Appl. Surf. Sci. 258, 3184 (2012).

58. S. E. Jacobo, P. G. Bercoff, C. A. Herme, and L. A. Vives, Mater. Chem. Phys. 157, 
124 (2015).

59. Y. Chen, A. Zhang, L. Ding, Y. Liu, and H. Lu, Compos. Part B Eng. 108, 386 (2017). 60. A. Hazarika, B. K. Deka, K. Kong, D. Kim, Y.-W. Nam, J.-H. Choi, C.-G. Kim, Y.B. Park, and H. W. Park, Compos. Part B Eng. 140, 123 (2018).

61. Q. Wu, H. Gao, Y. Zhang, and W. Shui, Compos. Part B Eng. 155, 83 (2018).

62. Y. Gao, X. Gao, J. Li, and S. Guo, Compos. Sci. Technol. 158, 175 (2018). 
Figures

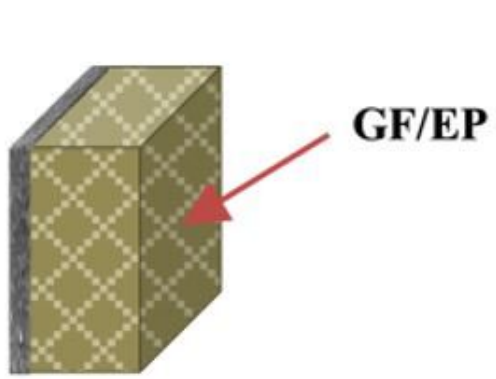

GF/EP/BP 100

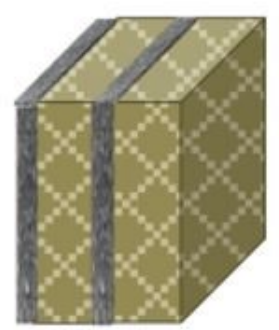

GF/EP/BP 110

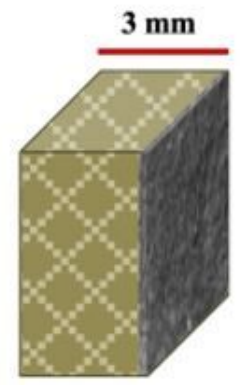

GF/EP/BP 001

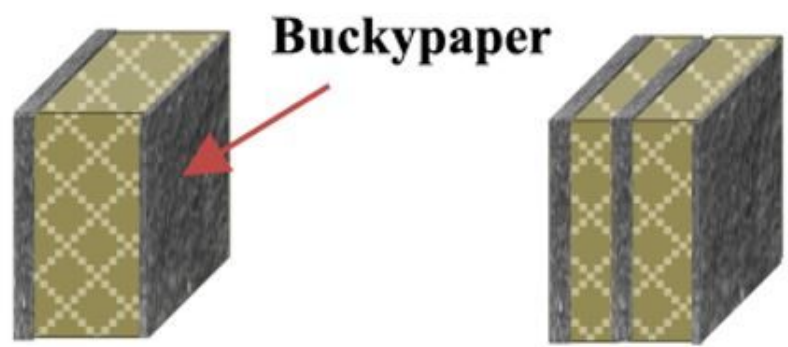

GF/EP/BP 101

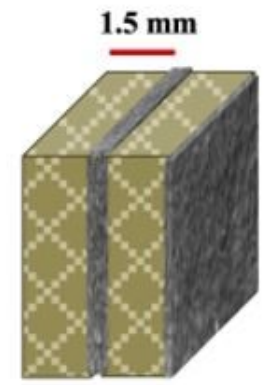

GF/EP/BP 011

Figure 1

Schematic configuration studied for GF/EP/BP laminates. 

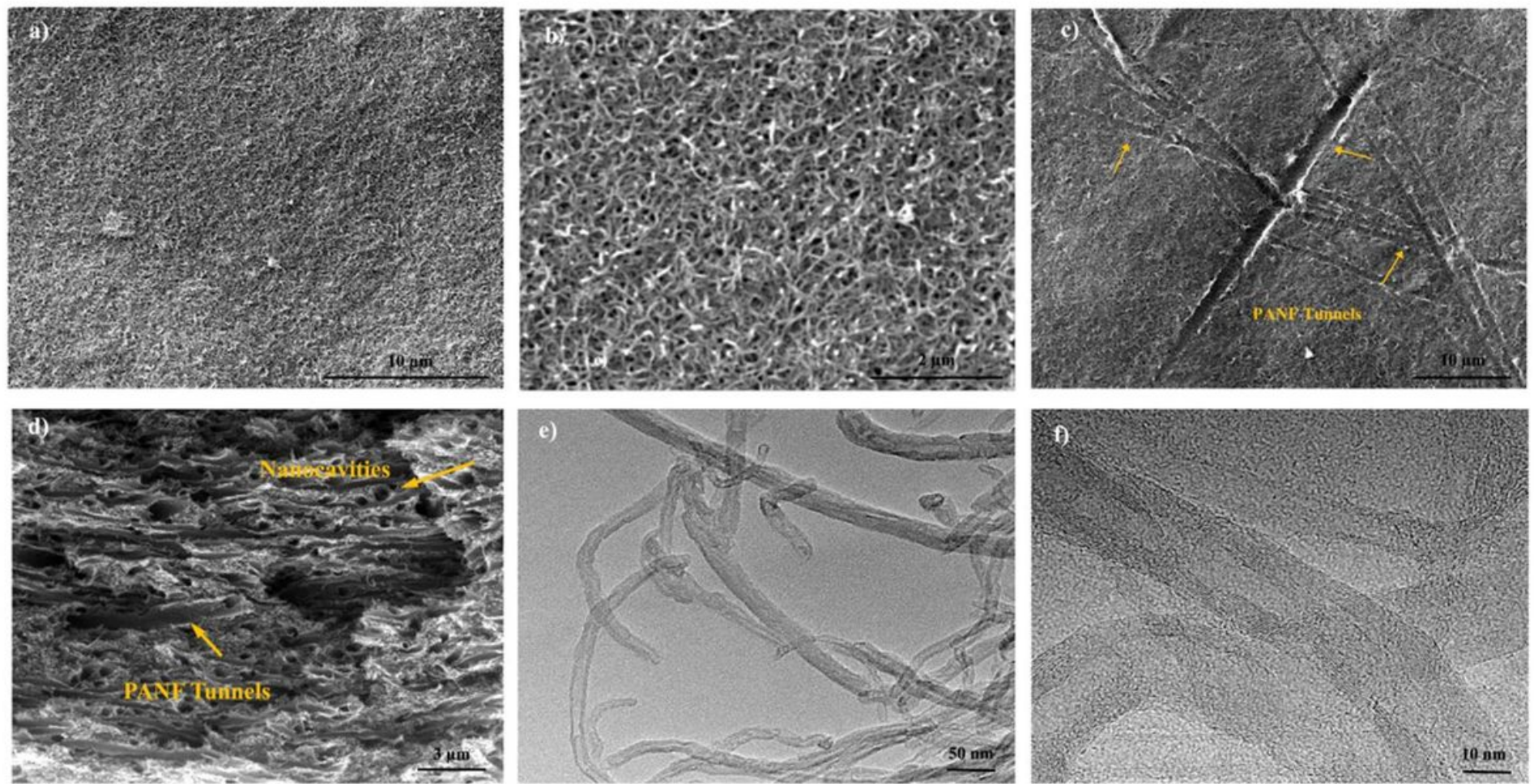

Figure 2

SEM images of buckypaper with different magnifications (a-b), PANF tunnels on the BP structure (c-d) and, HRTEM of the prepared buckypaper (e-f). 

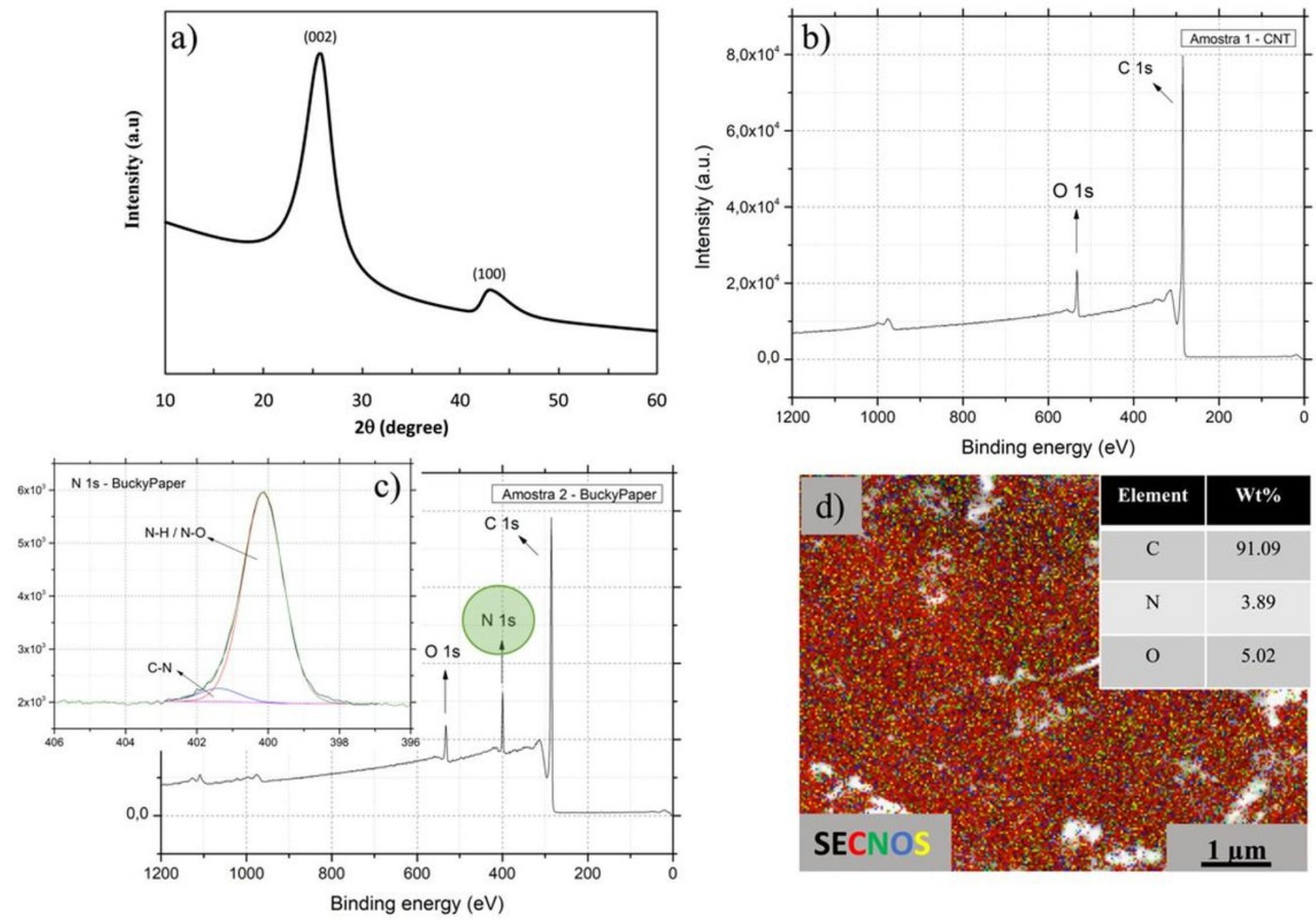

Figure 3

XRD pattern of MWCNT (a), XPS spectra of MWCNT (b) and BP (c), and EDS image of the buckypaper (d). 

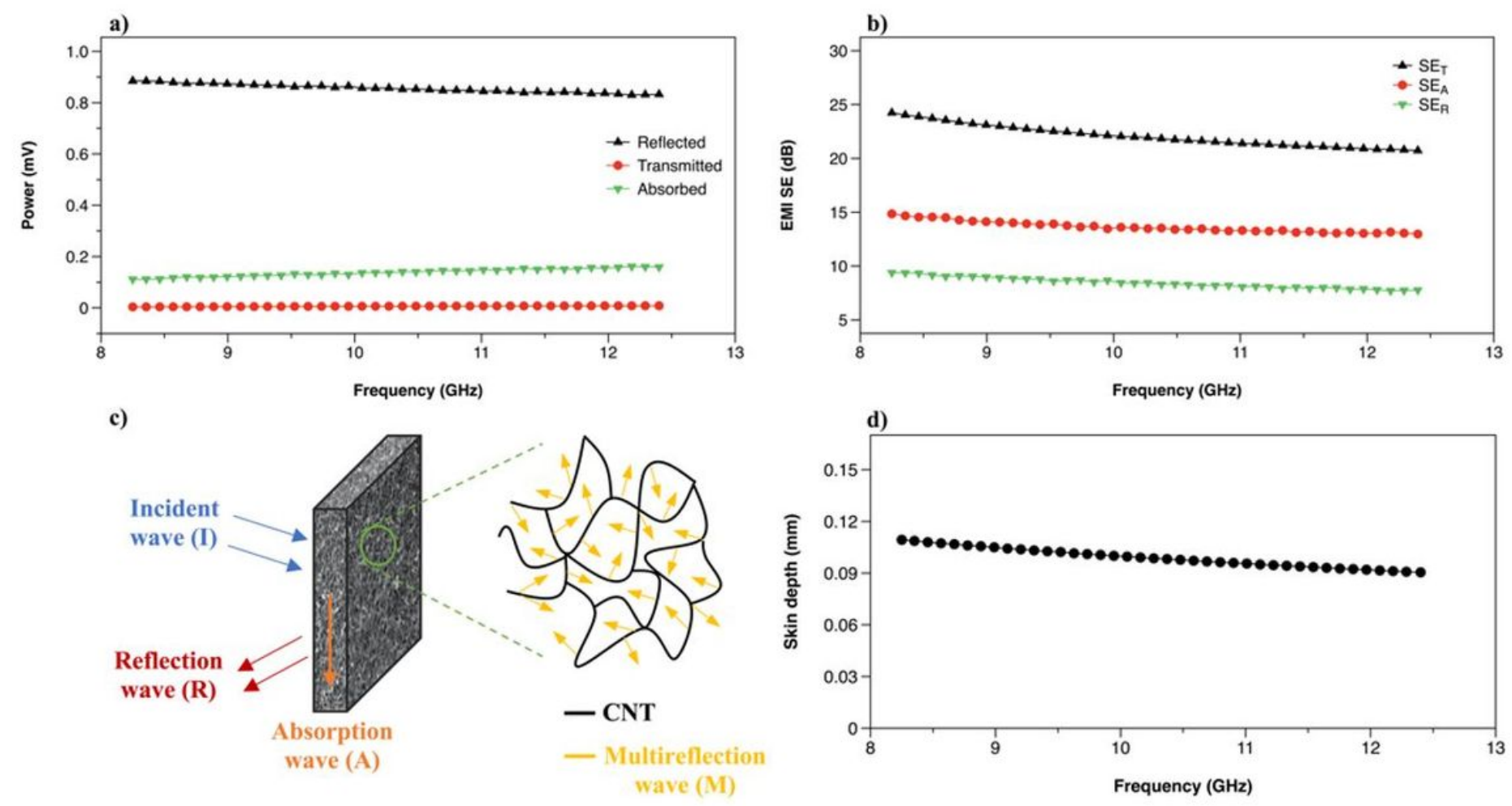

Figure 4

Power balance (a), EMI SE (b), shielding mechanism (c), and skin depth (d) of the prepared buckypaper.
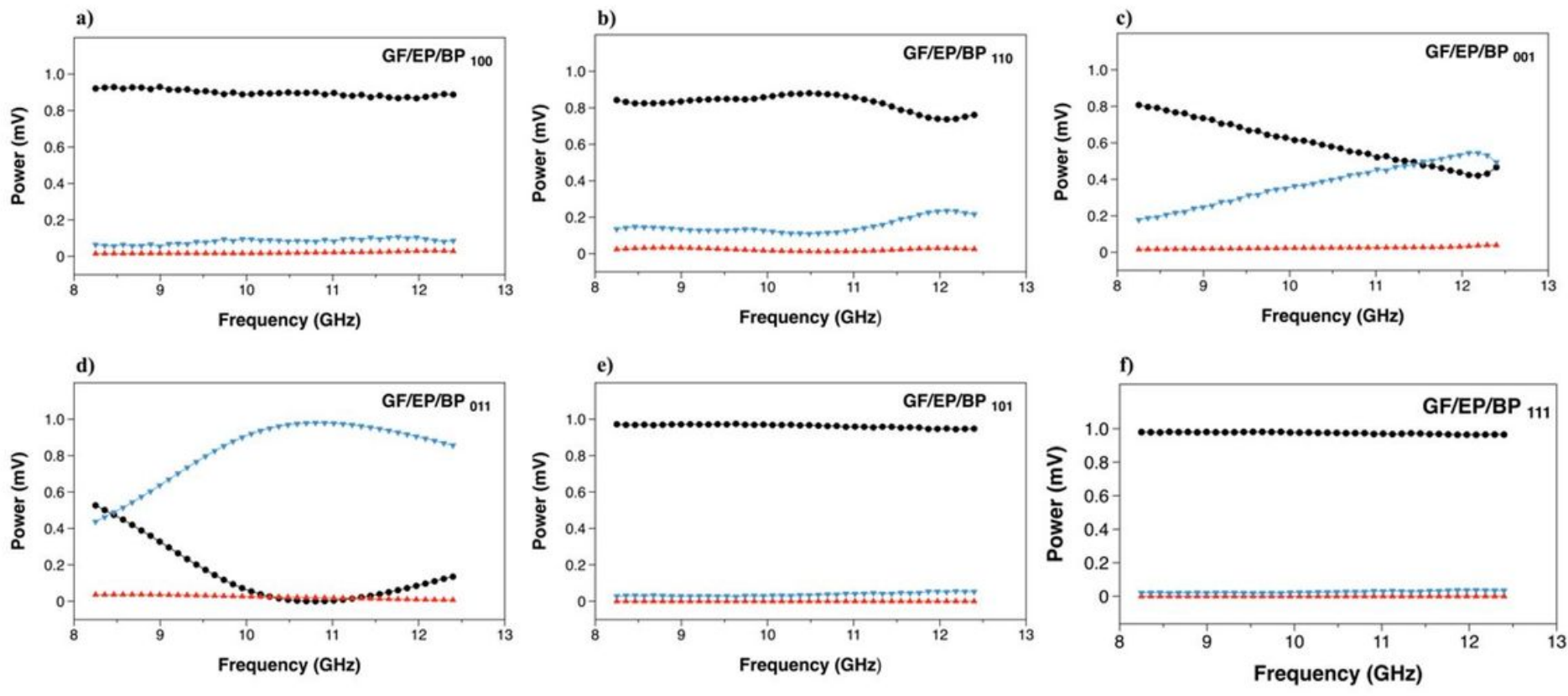

Reflected $\_$Transmitted - Absorbed

\section{Figure 5}


Power balance (reflection, transmission, and absorption components) of all composite samples over the X-band.
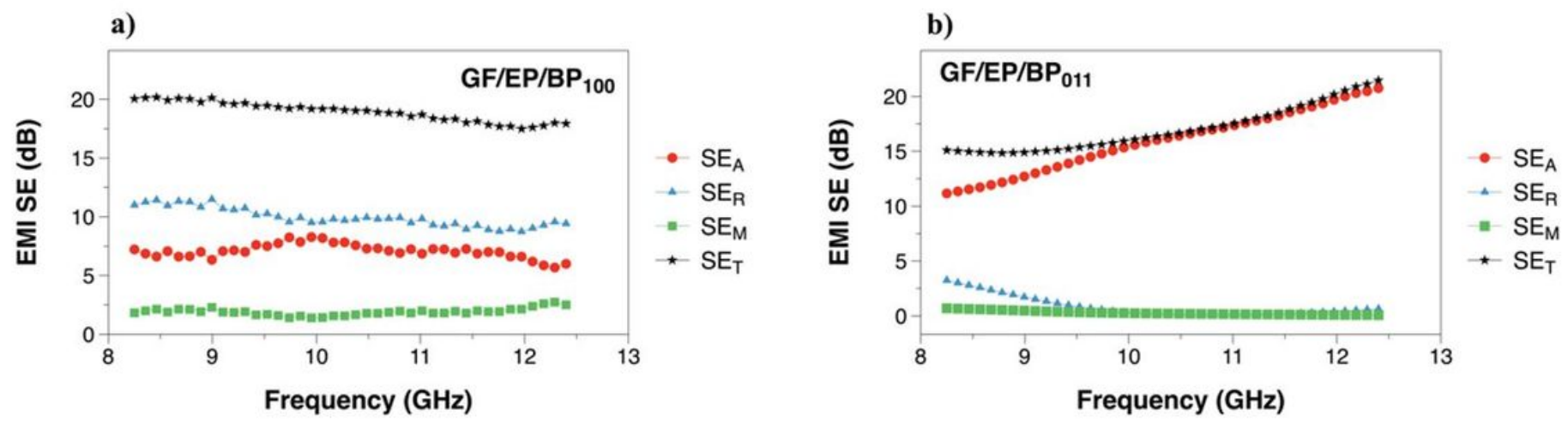

c)
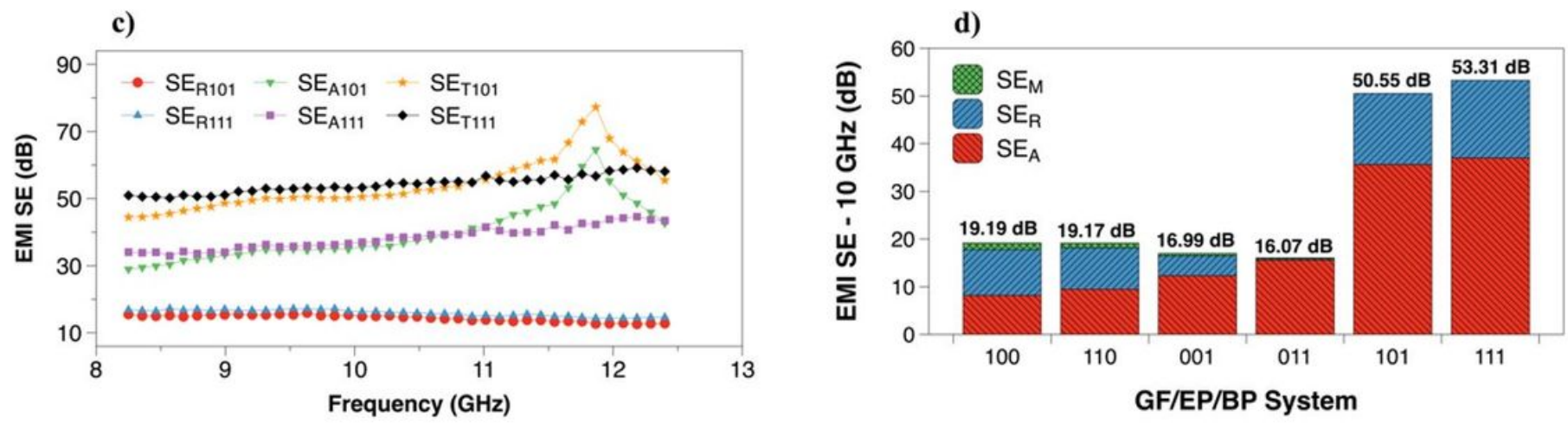

Figure 6

EMI SE of GF/EP/BP composites for 100 (a), 011 (b), 111 (c) and SEA, SER, SEM at the frequency of 10 $\mathrm{GHz}(\mathrm{d})$ for all studied samples. 
a)

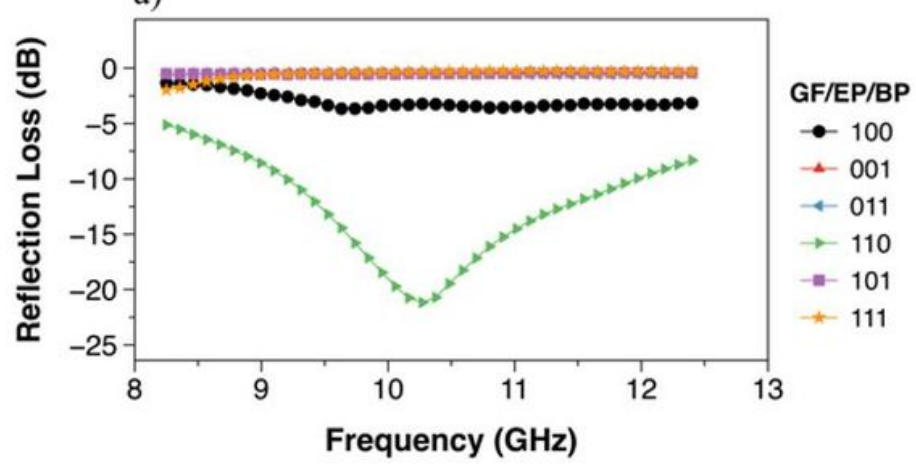

b)

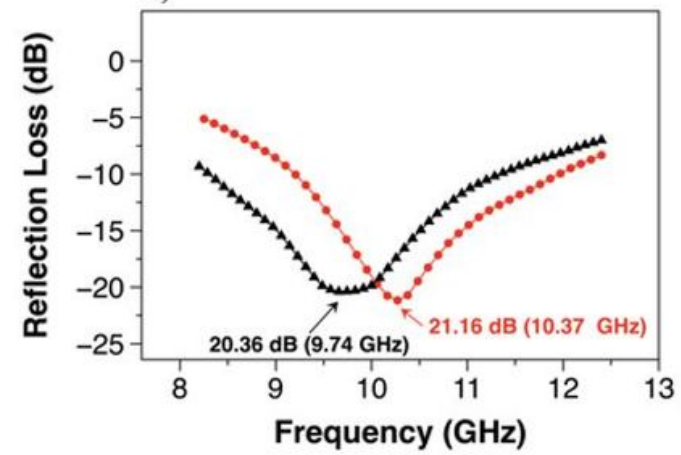

GF/EP/BP 110

- Experimental

- Simulation

c) EXPERIMENTAL
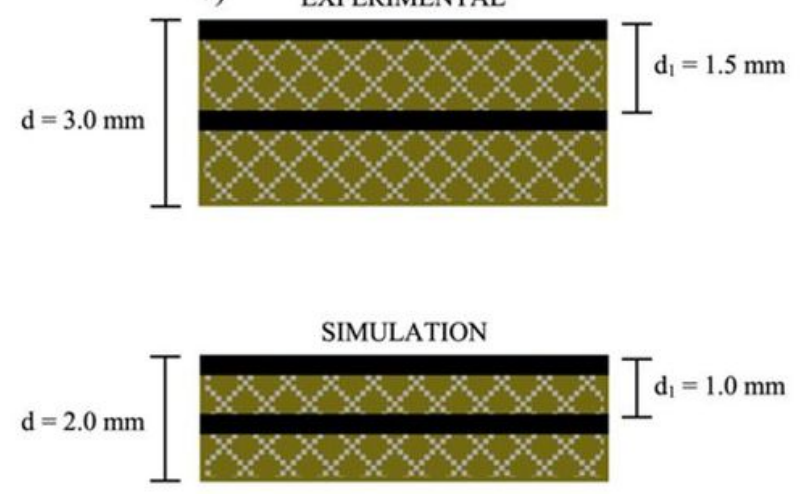

\section{Figure 7}

Reflection loss of all studied GF/EP/BP composites (a). Comparison between simulation and experimental results (b) configurations and dimensions (c) of GF/EP/BP110 laminate. 